\title{
ASSESSMENT OF TRANSACTION COSTS IN FARMER'S MANAGED IRRIGATION SYSTEM IN NEPAL
}

\author{
Ram Chandra Bhattarai, Ph.D.
}

\begin{abstract}
The paper attempts to estimate the transaction cost and compare it with production cost and value of output of crops. It also attempts to analyze the factors influencing the transaction cost. For this information was collected from field survey of 60 irrigation systems covering 360 households. The findings of the study show that the main element of transaction time is watching, waiting and negotiating time and which constitute more than 92 percent of the total transaction time. The study also shows that the transaction time is relatively low for Farmers Managed Irrigation System (FMIS) in Nepal. The transaction time is about $5 \%$ to that of total time required for the production of crops. The transaction time is high for the households cultivating the land at downstream of the canal compared to the households cultivating the land at upstream of the canal. In terms of crops transaction time for the cultivation of winter crops is three times higher than that of the summer crop.
\end{abstract}

Key Words: System, Households, Transaction cost, Repair and maintenance cost, Institution, Farm location, Kathmandu valley

\section{INTRODUCTION}

Agriculture is the main source of subsistence for most of the people in developing countries including Nepal. It contributes about $32 \%$ of the GDP and provides employment for more than two third of the population of the country. Nepal is famous for its farmer's managed irrigation systems (FMIS). There are about 16,000 FMIS and irrigate approximately 7, 14,000 ha. of cultivated area or $67 \%$ of the total irrigable area of the country. Historically the government of Nepal perceived irrigation development as being the domain of local concerns because of which farmers in disparate locations of the country organized themselves to construct, govern, operate and maintain a large number of irrigation systems (Lam, 1998; Shivakoti et. al, 2002).

Irrigation systems have two basic semi-public good features, that is, costly to exclude potential beneficiaries from using it and the use of water by one individual reduces the availability of water to others. Thus the irrigation systems are characterized as

* Mr. Bhattarai is Associate Professor of Economics, Patan Multiple Campus, Tribhuvan University, Nepal 
common pool resources and water allocation and provisions are two major sources of collective-action problems. Operation and maintaining of an irrigation system requires coordination among many farmers. Collective action problems arise easily when each farmers has the incentive to use more water and invest less in the system. These problems often result in poor maintenance as well as conflicts and anarchy in water allocation (Tang, 1992). Solution for such problem requires institutional arrangements to provide a structure of rules.

To develop mutually beneficial arrangements in irrigation, participants need basic information about the physical and technological characteristics of the water flow and water delivery facilities as well as information about the respective preferences of individual participants. The information they posses at any given time and their ability to get more information affect their ability to develop appropriate institutional arrangements to tackle their problems in water allocation and maintenance. Thus it is equally important to know the factors influencing the participation and formation of institutions for the effective management of irrigation water. Literature show that there is high transaction activities i.e. asset specificity, uncertainty and frequency; for the management of irrigation system collectively (Tang, 1992,). However, there is not any empirical study regarding transaction cost for these activities in Farmers Managed Irrigation System. Thus it is important to know the elements of transaction costs and its magnitude under the farmers managed irrigation system empirically.

\section{FMIS in Nepal}

Until 1980's, there was no formal recognition of the contribution of farmer's managed irrigation system (Pradhan, 2002). However, with the basic needs fulfillment program of the government during 1980s, there was felt need for high rate of agricultural development which was not possible without the development of irrigation. For this it was not possible to develop large infrastructure by the government for the desired rate of agricultural growth. Thus during 1980s government with different donor driven programs (e.g., Irrigation Line of Credit-ILC, Irrigation Sector Program-ISP), started to provide assistance to FMIS in different parts of the country and hence increased the record of irrigated area (Pradhan, 2002). Thus for a short period of time many of the FMIS came under the domain of Irrigation Department.

Similarly during 1960s and 1970s huge investments was made for the construction of irrigation canals with the support of external agency and were managed by the government. Despite sophisticated engineering infrastructure and presence of highly educated staffs, the performance of these government managed irrigation system was poor (APROSC, 1978). The result was severing deprivation of tail-enders and 
low productivity in these systems (WECS, 1982). In this context the devolution of responsibility for irrigation water resource management to local users' organization has gained increasing importance in Nepal. Government of Nepal (GON) enacted Water Resource Act, 1992, Water Resource Regulation, 1993 and Irrigation Regulation 1999 which require registering the canal, though it is being managed traditionally by farmers. The right over the source and the canal can be protected only after the registration as the act established the ownership of water to state. GON has also adopted the policy of not only transferring irrigation systems to farmers but also creating a strong institution of farmers for the management of irrigation water (NPC, 2007).

Against this backdrop, this paper attempts to estimate the transaction costs in Farmer's Managed Irrigation Systems in Nepal. The specific objectives of the study are:

a) to describe and explain major elements of transaction costs of Farmer's Managed Irrigation System (FMIS),

b) to assess the transaction cost in FMIS,

c) to assess relative share of the transaction costs as compared to production cost, and

d) to analyze major factors influencing the transaction costs incurred by households.

The next section of the paper provides review of literature. Description of the study area and the methodology adopted for the data collection and analysis of the data are presented in section three and results of the empirical findings are discussed in section four.

Transaction costs are related to those costs that arise when an individual exchange ownership rights to economic assets and enforce their exclusive rights. It is also defined as costs of searching out information, costs of bargaining over terms, and costs of making sure an agreement is actually carried out; also apply to liability systems in determining the appropriate amount of compensation; costs of all legal activities associated with gathering evidence, presenting a case, challenging opponents, awarding and collecting damages etc. (Field et. al., 1995).

There is absence of the literature on the transaction costs in farmer's managed irrigation system. Many studies are made on the effectiveness of institutional arrangements at the local level for managing common pool resources in developing countries (Wade, 1988; Bromley, 1989; Ostrom 1990, 1992; Agrawal, 2001). Some estimated the 
transaction costs related to co-management of fisheries, tank aquaculture, wildlife and community forestry (Kuperan et al., 1998; Sumalde and Pedroso et al., 2001, Senaratne, 2006, Mburu et. al., 2003; Adhikari and Lovett, 2006, Meshack et al., 2006).However studies that measure empirically the transaction costs of farmers managed irrigation system are not yet available. This is an interesting study, being the first detailed survey of transaction costs in Farmers Managed Irrigation System of Nepal.

\section{STUDY AREA AND METHODOLOGY}

\section{Study Area}

The study was conducted in three districts of Kathmandu Valley (Kathmandu, Lalitpur and Bhaktapur). Total population of Kathmandu valley is about 1.7 million. Of which, $60 \%$ reside within the urban centers and remaining $40 \%$ reside in the countryside of these districts. The irrigation canals exist only in villages of these districts. Total cultivable area in Kathmandu, Lalitpur and Bhaktapur is about 12,800 ha., 11069 ha. and 7,097 ha. respectively. Kathmandu valley is famous for its agricultural production. The major cereal crops of the valley are paddy, wheat, maize and millet. Similarly, potato, oilseeds and vegetables are the major cash crops of these valley districts. Among these crops paddy, wheat and potato need irrigation water. In Kathmandu irrigation water is needed for the plantation of paddy. After plantation, if there is normal rainfall it will be sufficient for the irrigation of paddy plants. The importance of irrigation water is mostly for early" paddy, wheat and winter potato*. Farmers need to stay continuously for about 12-24 hours for the irrigation of wheat and potato since during winter there will be no rain in Kathmandu. As such farmers need to give more time for watching, waiting and negotiating for the cultivation of wheat and potato in winter.

\section{Data Collection Strategy}

First total number of systems within all districts of Kathmandu Valley (Kathmandu, Lalitpur and Bhaktapur) was listed. Systems were categorized with VDCs they cover. Considering the VDCs served by the irrigation systems the systems were grouped with large (3 VDC and above), medium (2 VDCs) and small (1 VDC). Altogether there are 415 systems in Kathmandu valley and among them 51 are large, 122 are medium and 242 are small. Twenty systems from each category were selected randomly for the purpose of the study. The detail of the selection of the system is presented in Table 1.

\footnotetext{
* In some part of Kathmandu farmers plant paddy in May, so that they can cultivate potato twice after the paddy.

** The summer potato which is cultivated just after the harvesting of paddy does not need much water since the land is wet during this period and only winter potato needs irrigation.
} 
Table 1: Selection of System

\begin{tabular}{|l|l|l|l|}
\hline Systems & $\begin{array}{l}\text { Systems covering } \\
\text { village }\end{array}$ & $\begin{array}{l}\text { Total systems within } \\
\text { Kathmandu Valley }\end{array}$ & $\begin{array}{l}\text { No of systems selected } \\
\text { randomly }\end{array}$ \\
\hline Small & 1 & 242 & 20 \\
\hline Medium & 2 & 122 & 20 \\
\hline Large & 3 and above & 51 & 20 \\
\hline Total & & $\mathbf{4 1 5}$ & $\mathbf{6 0}$ \\
\hline
\end{tabular}

Out of these systems information on name and address of the households and the geography of the canal within these selected systems are collected. The large system was divided into three sub-system and farmers irrigating the canal were grouped as head, middle and tail. Similarly medium system was divided into two subsystems and farmers irrigating the canal were grouped as head and tail and all the users of the small system were considered as head users. Three households from each subsystem were selected for the purpose of understanding the household behavior. Altogether 360 households were selected randomly from these six subsystems of three types of system. The detail of selection strategy of households is presented in the Table 2 .

Table 2: Household Selection Strategy

\begin{tabular}{|l|l|l|l|}
\hline \multirow{2}{*}{ Systems } & \multirow{2}{*}{ Households selected } & \multicolumn{2}{l|}{ Systems and Households selected } \\
\cline { 3 - 4 } & & Systems & Households \\
\hline Small systems & 3 from whole system & 20 & 60 \\
\hline Medium systems & 6 (3 from head and 3 from Middle) & 20 & 120 \\
\hline Large systems & $\begin{array}{l}\text { (3 from head, 3 from Middle and 3 } \\
\text { from tail end users) }\end{array}$ & 20 & 180 \\
\hline Total & & 60 & 360 \\
\hline
\end{tabular}

Three types of questionnaire ${ }^{* * *}$ were prepared for the purpose of the study. Questionnaires were pretested before the use. Instructions handbook for the enumerator were also prepared for the filling of all three types of questionnaire.

\subsection{Elements of Transaction cost and its Measurement}

Transaction costs are measured at both institutional and household level. Institutional transaction costs are measured in terms of ex-post and at ex-ante stage. Transaction costs like formation cost, are the ex-ante cost which arise during the formation of an organization. It includes meeting cost, registration costs, negotiation costs etc. On the other hand ex-post cost is the time cost for general meetings, time cost for meetings, time cost for the conflict resolution and communications (Bhattarai, 2007).

\footnotetext{
*** a) system level questionnaire, b) sub-system (Head, Middle and Tail) level questionnaire and c) household level questionnaire.)
} 
Transaction costs are also measured at the household level. These costs include the time cost for watching, waiting and negotiating cost during irrigation, time cost for conflict resolution and meeting costs (Bhattarai, 2007). Both types of costs are estimated separately. Detail of the method for the measurement of transaction cost is presented in Table 3.

Table 3 :Methods of Estimating Transaction Costs

\begin{tabular}{|c|c|c|c|c|}
\hline Transaction & $\begin{array}{l}\text { Nature of } \\
\text { Transactions/ elements } \\
\text { of transaction }\end{array}$ & Nature of Cost & Approach & $\begin{array}{l}\text { Cost } \\
\text { estimation }\end{array}$ \\
\hline $\begin{array}{l}\text { Formation of } \\
\text { Organization }\end{array}$ & $\begin{array}{l}\text { Meetings/ dealing with } \\
\text { stake holders/ }\end{array}$ & Time for meetings & $\begin{array}{l}\text { Value of time } \\
\text { Wage } \\
\text { rate*time }\end{array}$ & $\begin{array}{l}\text { Interest rate } \\
\text { as annual } \\
\text { cost }\end{array}$ \\
\hline $\begin{array}{l}\text { Formation of } \\
\text { Organization }\end{array}$ & $\begin{array}{l}\text { Dealing with government } \\
\text { offices }\end{array}$ & $\begin{array}{l}\text { Travel cost, } \\
\text { registration cost, } \\
\text { statute preparation } \\
\text { cost }\end{array}$ & $\begin{array}{l}\text { Monetary } \\
\text { expenditure }\end{array}$ & $\begin{array}{l}\text { Interest rate } \\
\text { as annual } \\
\text { cost }\end{array}$ \\
\hline $\begin{array}{l}\text { Ensuring the } \\
\text { implementation } \\
\text { of decisions }\end{array}$ & $\begin{array}{l}\text { Meetings/ dealing with } \\
\text { agents/ communication/ } \\
\text { conflict resolution }\end{array}$ & Time for meetings & $\begin{array}{l}\text { Wage } \\
\text { rate*time }\end{array}$ & $\begin{array}{l}\text { Opportunity } \\
\text { cost }\end{array}$ \\
\hline $\begin{array}{l}\text { Protecting and } \\
\text { negotiating }\end{array}$ & $\begin{array}{l}\text { Watching, Waiting and } \\
\text { Negotiating }\end{array}$ & Time & $\begin{array}{l}\text { Wage } \\
\text { rate*time }\end{array}$ & $\begin{array}{l}\text { Opportunity } \\
\text { cost }\end{array}$ \\
\hline
\end{tabular}

To calculate the monetary transaction costs arising to the households due to their participation in meetings, the average wage rate was multiplied with the reported time spans. This approach is justified by the fact that the households have possibility to work outside their farm throughout the year, since the study area is around the Kathmandu Valley and there is always possibility to work as labour in urban area. Thus the opportunity costs of participation indeed arise throughout the year and that the wage rate can be used as a proxy for these costs (Mburu, 2003). While estimating the opportunity cost average wage rate for pick and slack season was calculated and used.

Similarly the formation cost are one time cost and calculated on the basis of time and resources devoted by farmers at the time of formation. These costs are of fixed nature. Hence to estimate the annual costs for the formation lowest interest rate that the farmers need to pay to the banks to borrow the money $(9 \%)$ is taken as proxy and only the amount of interest is considered to estimate the annual transaction cost of formation. These costs are converted into hour time dividing by the hourly wage rate to estimate the transaction time.

Total annual transaction time was estimated by adding both system level annual transaction time and household level annual transaction time. For this purpose, system level total annual transaction time was divided by the total number of households within the system and added to the household level transaction time. While doing 
so the general meeting time at system level is not added to the total transaction time since such time cost is reflected in the meeting time cost at the household level. While estimating the transaction cost and repair and maintenance cost, time devoted in hours is estimated and the hours are converted into days by considering 7 hours as one working day.

Attempt is made to compare the transaction time cost with total human labour required for the production of three major crops i.e. paddy, wheat and potato. Total human labour required for the production of crops is taken from the secondary source i.e. from the published data of Ministry of Agriculture and Cooperatives (GoN/MoAC, 2007).

\section{ANALYSIS OF FINDINGS}

The analysis of findings is divided into three parts. The first part discusses the descriptive analysis e.g. physical condition, institution and government assistance and general characteristics of the household. The second part deals about relative share of transaction days and repair and maintenance days to that of total human labour required for the production of crops. The third part shows the econometric models and its findings. In this part we attempt to show the impact of farm locations as well as other explanatory variables on transaction cost.

\section{Physical Condition of the Canal}

Most of the studied systems were constructed many years back by the ancestors of the present users and few were constructed by direct bilateral assistance. The source of most of the canals was rivers and streams, however, $13 \%$ canals originated from the main source of the water $(\mathrm{Mul})$ from where the stream or river originates. To understand the infrastructure conditions of the canal, information was collected regarding concrete dam in the intake point of the canal, lining of the canal, and rocky part of the canal and leakage situation. Considering all these variables the infrastructure situation of the canals was categorized into three categories i.e. good, fair and poor. The findings shows that about $63 \%$ of the households were using the canal with poor infrastructure, whereas only $5 \%$ of the surveyed households were using the canal with good infrastructure and remaining one third households were using the canal with medium infrastructure.

This shows that most of the canals are in poor conditions i.e. there is leakage in canals due to the lack of proper lining; canals are not able to consolidate water from the intake point due to lack of proper dam at the intake point of the canal. Similarly canals which pass from the rocky part have lot of leakages and farmers are facing difficulty in repairing the canal without external support. During field survey it was also found that farmers face difficulty in controlling the leakages where the canal was repaired with external resources i.e with cement, sand and stone. Of the total systems surveyed $50 \%$ were rehabilitated during last 30 years. Among these rehabilitees about two thirds received government support, whereas only $10 \%$ were repaired by the user farmers only and remaining systems were repaired by users with partial support by the government or NGO or INGOs. Average irrigated area is highest in large system 
(151 ha.) and lowest in small system (15 ha.). Similarly average length of the canal is 3.05 $\mathrm{km}$, and it is also highest $(4.2 \mathrm{~km}$.) for large, and lowest $(2.2 \mathrm{~km}$.) for small canals.

Table 4 : Descriptive Information Related to Institutions

\begin{tabular}{|l|l|l|}
\hline Attributes & Number & Percent \\
\hline Total systems having formal organization & 31 & 52 \\
\hline Total systems without formal organization & 29 & 48 \\
\hline $\begin{array}{l}\text { Among the systems having formal organization systems } \\
\text { having registered WUA }\end{array}$ & 21 & 68 \\
\hline Systems having informal WUA & 9 & 29 \\
\hline No Election after the formation of WUA & 21 & 100 \\
\hline No rule for the exclusion of non members & 21 & 100 \\
\hline Existence of institutions within the village of the system & 57 & 97 \\
\hline $\begin{array}{l}\text { Gender of Chairman of WUA } \\
\text { Male }\end{array}$ & 30 & 97 \\
\hline
\end{tabular}

Source: Field Survey, 2007-08

\section{Institutions and Government Support}

The systems which have no formal organization did not receive any government support for the repair and maintenance of the canal. Only those systems which are formally organized are getting the assistance from the government. All irrigators are eligible to get the membership and they never collect the membership fee and no possibility of exclusion for non-member. Most of the formal institutions were formed after 1990. The organization formation date and the date of selection of the present executive is same. My field experience shows that the motivating factor to organize and register the institution was just to get the resources from external sources and repair the canal. Again government could not provide the resources as needed for the repair of canal as such canals are partially repaired.

\section{General Characteristics of the Surveyed Households}

Among the total 360 households most of the households are headed by male and majority of them are illiterate. The main occupation of about two thirds of the household head is agriculture and remaining are employed as salaried job or in private business. Average number of household member within the surveyed system is nearly 6 . The ratio of average of male and female is 1:1. The average number of students within the household is 2 (Table 5). About one third (31\%) of the total surveyed household are reported to be the member of any organization within the village. However, only about $14 \%$ households are reported to be member of water users association (WUA) (Table 4). Even in case of surveyed registered organization only $37 \%$ of the households are member of WUA. 


\section{Table 5: Demographic Features of Households}

\begin{tabular}{|l|l|l|}
\hline Household Parameter & No of Households & Percent \\
\hline Head of the Household & 311 & 86 \\
\hline Eale & & \\
No formal Education & 183 & 51 \\
Grade 1-5 & 46 & 13 \\
Grade 6-10 & 94 & 26 \\
Grade 11-14 passed & 33 & 9 \\
Master Completed & 2 & 1 \\
\hline Main Occupation (Head of HH) & & \\
Agriculture & 238 & 66 \\
Salaried Employed & 47 & 13 \\
Private Business & 12 & 4 \\
Aged & 50 & 14 \\
Pension & 5 & 1 \\
Wage Worker & 4 & 1 \\
Other & 4 & 1 \\
\hline Member of any organization & 111 & 31 \\
Member of WUA & 50 & 14 \\
\hline
\end{tabular}

Source: Field Survey, 2007-8

\subsection{Transaction Cost, Repair and maintenance cost and total production cost for different crops.}

Broadly there are five category of transaction cost i.e. watching, waiting and negotiating, meeting, conflict resolution, communication and formation cost. Among them watching, waiting and negotiating is the main cost which constitutes about $92 \%$ of the total transaction cost. The second category is the meeting cost which constitute about $7 \%$ of the total transaction cost and remaining are the conflict resolution, formation and communication cost (Figure 1).

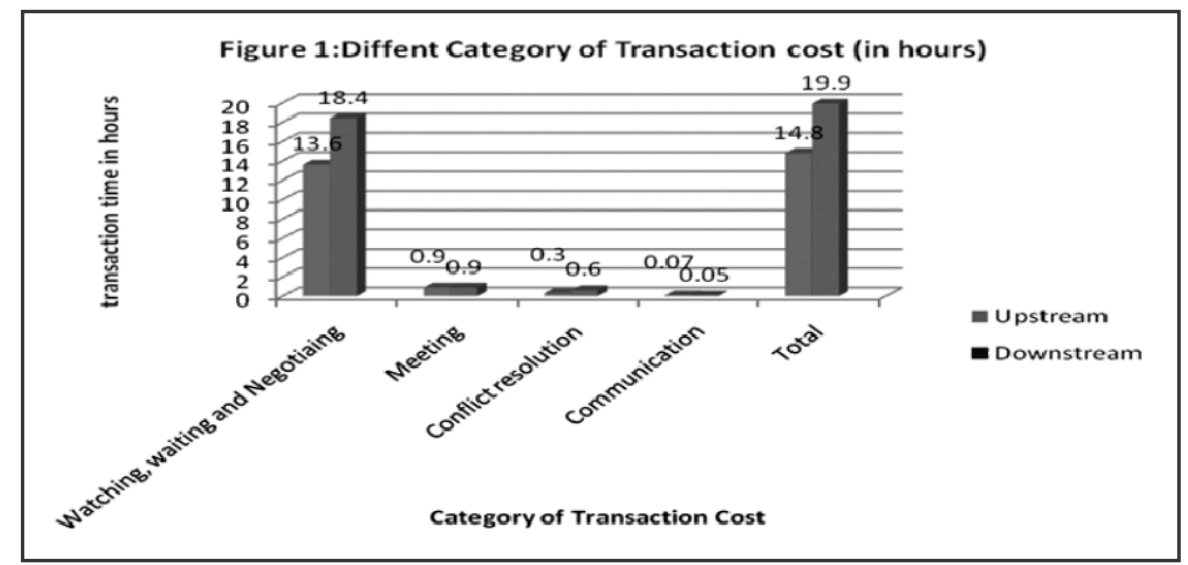


The transaction time is relatively low compared to the total human labour required for the production of crops. The share of transaction time to that of total time required for the production of crops is about $4 \%$ for upstream and it is about $6 \%$ for downstream households (Figure 2 and 3). The transaction time for winter crops is three times higher than the transaction time for summer crops It is mainly because in summer there is monsoon rain and less irrigation water is needed from the canal and hence less watching, waiting and negotiating costs. On the other hand in winter there is no rain water and farmers need to devote more time for watching, waiting and negotiating to irrigate the crops. If we compare the transaction cost with the total value of output it is still lower. It is only about one percent of the total value of output. The share of repair and maintenance time is still lower and is less than $2 \%$ of the total time required for the production of crops for both upstream and downstream households (Figure 2 and 3).
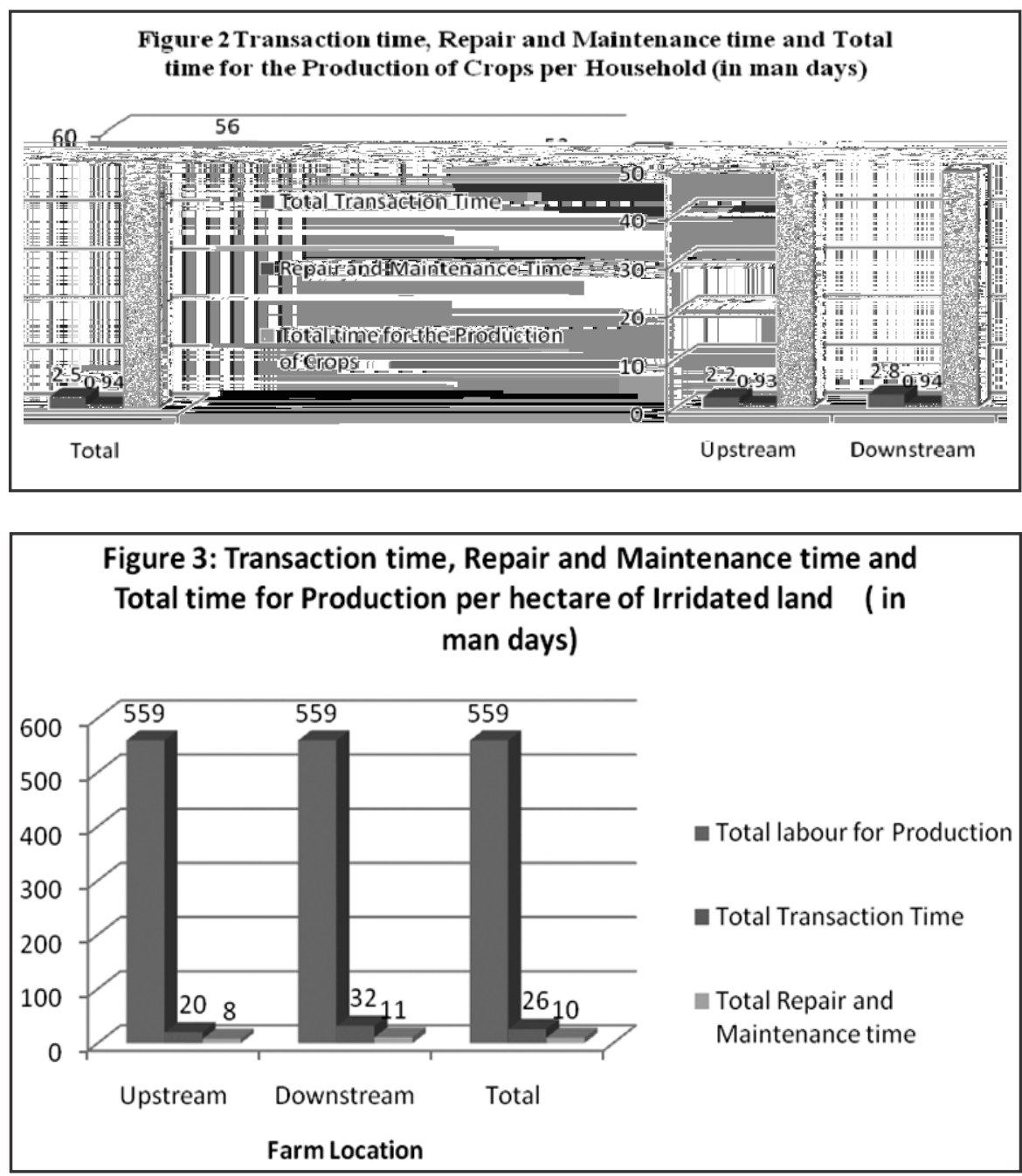
As there are not any studies regarding transaction cost in FMIS it is difficult to compare. However if we compare the theoretical literature on FMIS (Ostrom, 1992; Tang, 1992) the transaction costs are found to be relatively low. The findings of the present study are consistent with the findings of Mburu et al (2003) which shows relatively lower transaction cost as compared to other costs to the landowners for the collaborative wildlife management in Kenya. Whereas the transaction costs for forest users group in case of community forestry in Nepal and in Tanjania are found to be relatively high (Adhikari and Lovett, 2006; Meshak, 2006) to that of the present study.

\section{ACKNOWLEDGEMENT}

The author is thankful to South Asian Network for Development and Environmental Economics for providing financial support to carry out the research work.

\section{References}

Adhikari, B., Jon C. Lovett (2006). Transaction costs and Community -based Natural Resource Management in Nepal. Journal of Environmental Management 78: 5-15.

Agrawal, Arun (2001). Common Property Institutions and Sustainable Governance of Resources, World Development 29(10): 1649-1672

APROSC (1978). Irrigation Impact Evaluation Study: Manusmara Irrigation Project, Agricultural Projects Services Centre, Kathmandu

Bhattarai, R.C. (2007). Transaction Costs in Farmer Managed Irrigation Systems in Nepal: A case of Some Selected FMIS in Kathmandu Valley' in Prachanda Pradhan et al (eds.) Irrigation in Transition: Interacting with Internal and External Factors and setting Strategic Actions, Proceedings of the Fourth International Seminar Held on 6-7 November 2006, Kathmandu Nepal, Farmer Managed Irrigation Systems Promotion Trust, Kathmandu, Nepal

Bromley, Daniel W. (1989). Economic Interest and Institutions: The conceptual foundations of public policy, Basil Blackwell

Dulal, S. and Pradhan, P. (2002). Report on the Inventory of Irrigation Systems in Kathmandu District, Nepal.

Kuperan, K., Mustapha, N., Abdullah, R., Pomeroy, R.S., Genio, E. and Salamanca, A. (1998). Measuring Transaction Costs of Fisheries Co-management, Paper Presented at the Seventh Biennial Conference of the International Association for the Study of Common Property, Vancouver.

Lam, W. F. (1998). Governing Irrigation Systems in Nepal, Institute for Contemporary Studies, Oakland, California

Mburu, J., Birner, R. and Zeller, M.(2003). Relative Importance and Determinants of Landowners' Transaction Costs in Collaborative Wildlife Management in Kenya: an Empirical Analysis, Ecological Economics 45: 59-73 
Meshak, C.K., Adhikari, B. , Doggart, N., and Lovett, J.C. (2006). Transaction Cost of Community Based Forest Management, empirical evidence from Tanjania, African Journal of Ecology, $44: 648-647$

NPC .(2007).Interim Plan 2007/8-2009/10. Government of Nepal, National Planning Commission, Nepal

Ostrom, E. (1990).Governing The Commons: The Evolution of Institutions for Collective Action, Cambridge University Press, Cambridge, New York.

Ostrom, E. (1992). Crafting Institutions for Self-Governing Irrigation Systems, Institute for Contemporary Studies, San Francisco, California.

Pradhan, P. (2002). Eroding Social Capital through Incompatible Legal and Institutional Regimes: Experience from Irrigation systems in Nepal, an unpublished paper, Workshop in Political Theory and Policy Analysis, Indiana.

Pradhan, P. (1989) Patterns of Irrigation Organization in Nepal: Case Study of 21 Farmer Managed Irrigation System in Nepal, IIMI, Colombo.

Pradhan, R. (2003). A History of Water Management in Nepal: Culture, Political Economy and Water Rights. in Rajendra Pradhan (ed.) Law History and Culture of Water in Nepal, Legal Research and Development Forum (FREEDEAL), Kathmandu, Nepal.

Shivakoti, G. P. and Ostrom, Elinor (eds.) (2002). Improving Irrigation Governance and Management in Nepal, Institute for Contemporary Studies, Oakland, California.

Shivakoti, G., Giri, K. and Ostrom, Elinor (1992).Farmer-Managed Irrigation Systems in Nepal: The impact of interventions, Ministry of Agriculture and Winrock International. Research Report Series, Number 18

Sumalde, Z. M. and Pedroso, S. L. (2001). Transaction Costs of Community-based Coastal Resource Management Program in San Miguel Bay, Philippines; Economy and Environment Program for South East Asia (EEPSEA) Research Report.

Tang, S. Y. (1992). Institutions and Collective Action, Self-Governance in Irrigation, Institute of Contemporary Studies, San Francisco California.

Wade, R. (1988). Village Republics- Economic Conditions for Collective Action in South India, Institute for Contemporary Studies, San Francisco, California

WECS (1982). Performance Review of Public Sector Intensive Irrigation Based Agricultural Development Projects, Water Resource and Energy Commission, HMG/N Kathmandu, Nepal. $<<$ http://www.indiana.edu/-issap/Drafts/Kuperan.pdf $\gg>$ 